\title{
Decreased expression of microRNA-223 promotes cell proliferation in hepatocellular carcinoma cells via the insulin-like growth factor-1 signaling pathway
}

\author{
CHENG ZHANG $^{1}$ and JIAMIN ZHANG $^{2}$ \\ ${ }^{1}$ Department of Surgery, Division of Hepatobiliary and Pancreatic Surgery, \\ The First Affiliated Hospital, School of Medicine, Zhejiang University, Hangzhou, Zhejiang 310058; \\ ${ }^{2}$ Department of Hepatobiliary and Pancreatic Surgery, Jinhua People's Hospital, Jinhua, Zhejiang 321000, P.R. China
}

Received December 28, 2016; Accepted December 8, 2017

DOI: $10.3892 /$ etm.2018.5929

\begin{abstract}
Hepatocellular carcinoma (HCC) is one of the most harmful types of cancer. Previous studies have demonstrated that microRNA (miR)-223 is downregulated in the serum and tumor tissue of patients with HCC. The present study aimed to investigate the regulatory role of miR-223 on insulin-like growth factor-1 receptor (IGF-1R) and downstream factors in HCC. The Hep3B cell line was transfected with miR-223 mimic and inhibitor. Following transfection, cell proliferation was analyzed using a cell counting kit 8 assay and cellular apoptosis was assessed using flow cytometry. The expression of key molecules in the IGF-1 signaling pathway, including IGF-1R, protein kinase B (Akt) and extracellular signal-regulated kinase (ERK) were determined using reverse transcription-quantitative polymerase chain reaction and western blot analysis. The results demonstrated that the mRNA and protein levels of IGF-1R were decreased in cells transfected with miR-223. Transfection with miR-223 also decreased cell proliferation and promoted cell apoptosis. Expression of total Akt and ERK, and their active forms phosphorylated Akt and ERK, were also downregulated following transfection with miR-223. By contrast, transfection with miR-223 inhibitor did not induce any effects on Hep3B cell proliferation and apoptosis, and did not affect the expression of key molecules in the IGF-1 pathway. Therefore, the results of the present study indicate that miR-223 decreases the proliferation and promotes the apoptosis of HCC cells. Its molecular mechanism of action may at least partially occur via the direct regulation of IGF-1R and indirect reduction of the downstream molecules Akt and ERK.
\end{abstract}

Correspondence to: Dr Jiamin Zhang, Department of Hepatobiliary and Pancreatic Surgery, Jinhua People's Hospital, 228 Xinhua Road, Jinhua, Zhejiang 321000, P.R. China

E-mail: zjm0323001@hotmail.com

Key words: hepatocellular carcinoma, microRNA-223, proliferation, apoptosis, insulin-like growth factor-1 receptor

\section{Introduction}

Hepatocellular carcinoma (HCC) is one of the most harmful types of cancer in humans; it is highly malignant and the prognosis of patients is poor (1). Recently, the incidence and mortality rates of $\mathrm{HCC}$ have been increasing, particularly across Eastern Asia, including in China. According to data taken from the National Central Cancer Registry in 2015, there were 466,100 new HCC cases and 422,100 HCC-associated mortalities in China in 2015, making HCC one of the top five malignant tumors in the incidence and mortality rates (2). The median survival time following HCC diagnosis is very short (usually $<6$ months) as the tumors are difficult to resect, due to high recurrence rates following surgery, and due to poor responses to chemotherapy and radiotherapy (3). Currently the molecular mechanisms that lead to the onset, development and metastasis of HCC remain to be elucidated.

It has been suggested that microRNAs (miRNAs) may be used as diagnostic and prognostic biomarkers for various types of tumors. miRNAs are endogenous, evolutionarily conserved, serum stable, non-coding RNAs (4); these characteristics mean that they are well suited to be used as biomarkers. miRNAs are also key regulators of gene transcription. Therefore, determining the regulatory mechanisms of miRNAs may improve understanding of cancer pathogenesis. Genome-wide miRNA profiling studies have revealed that there are numerous differentially expressed miRNAs in HCC, including miR-223 $(5,6)$. Furthermore, it has been demonstrated that the expression of miR-223 is reduced in HCC liver biopsy specimens compared with normal adjacent liver tissues $(6,7)$.

The increased expression of miR-223 is usually observed in cells with a myeloid lineage, as miR-223 serves an important role in granulopoiesis (8). The aberrant expression of miR-223 has been identified in leukemia and lymphoma (9). In addition, miR-223 is involved in the tumorigenesis of solid types of cancer; it was demonstrated that the overexpression of miR-223 inhibits HeLa cell proliferation and tumor growth in nude mice (10). This inhibitory role of miR-223 has also been observed in other tumors, including osteosarcoma (11). In HCC, the downregulation of miR-223 is correlated with the upregulation of stathmin1, a potential target of miR-223 
that is frequently overexpressed in cancer (6). Insulin-like growth factor-1 receptor (IGF-1R) is another potential target of miR-223; eosinophil production is increased in miR-223-/- mice, potentially due to the effects of miR-223 on IGF-1R (12).

IGF-1R is a key protein involved in the IGF-1 signaling pathway and is a highly conserved regulatory module involved in cell proliferation, differentiation and metabolism (13). IGF-1 is primarily secreted by the liver following stimulation by the growth hormone (14). It binds to its receptor IGF-1R, which is a transmembrane receptor tyrosine kinase and is activated by phosphorylation. Activation of IGF-1R leads to the downstream activation of the protein kinase $\mathrm{B}(\mathrm{Akt})$ and extracellular signal-regulated kinase (ERK) signaling pathways, two pathways that are linked to the development of numerous types of cancer including prostate cancer, gastric cancer, non-small cell lung cancer, ovarian cancer and HCC (15). The dysregulation of IGF-1R has been identified in multiple malignant tumors, including HCC, prostate and pancreatic cancer (16).

Based on these previous reports, it was hypothesized that the IGF-1 signaling pathway may mediate the regulatory role of miR-223 in HCC. In the present study, the role of miR-223 in cell proliferation, as well as its possible influence on IGF-1R, Akt and ERK, was investigated.

\section{Materials and methods}

Cell culture. The HCC cell line Hep3B [hepatitis B virus (HBV)-positive and hepatitis C virus (HCV)-negative; ATCC, Manassas, VA, USA] was used in the current study. Cells were cultured in Dulbecco's modified Eagle's medium (Gibco; Thermo Fisher Scientific, Inc., Waltham, MA, USA) supplemented with $10 \%$ (v/v) fetal bovine serum (Gibco; Thermo Fisher Scientific, Inc.). The cells were incubated were at $37^{\circ} \mathrm{C}$ in a humidified hood with $5 \% \mathrm{CO}_{2}$.

Cell transfections. The predicted binding sites between miR-223 and IGF-1R were obtained using the TargetScanHuman online software 7.1 (http://www.targetscan.org/vert_71/). All transfections were performed using Lipofectamine ${ }^{\circledR} 2000$ (Invitrogen; Thermo Fisher Scientific, Inc.). Cells were grown to $\sim 70 \%$ confluence and divided into four groups: The blank (BL) control group in which cells were treated with culture media; the miR-223 mimic group in which cells were transfected with 100 pmol miR-223 mimic (5'-UGUCAGUUUGUC AAAUACCCC-3'); the miR-223 inhibitor group in which cells were transfected with 100 pmol miR-223 inhibitor (5'-UGG GGUAUUUGACAAACUGACA-3'); the NC group in which cells were transfected with 100 pmol non-specific control RNA (5'-CAGUACUUUUGUGUAGUACAA-3'). Nucleotides were designed and synthesized by Shanghai GenePharma Co. Ltd. (Shanghai, China). The cells were harvested $48 \mathrm{~h}$ after transfection for RT-qPCR, western blot and cell apoptosis analyses.

Tumor samples. A total of $30 \mathrm{HCC}$ tumor tissue samples were used to analyze the levels of miR-223 and IGF-1R in HCC. Samples were randomly selected from the pathology department of the First Affiliated Hospital to
Zhejiang University (Hangzhou, China). Tissue samples were collected from 30 patients $(49 \pm 11$ years old; 24 males and 6 females) that underwent curative surgery for HCC at the hospital. The sample collection dates were from August 2012 to June 2015. Samples were stored in liquid nitrogen $\left(-196^{\circ} \mathrm{C}\right)$ until further experiments. The study protocol was approved by the Ethics Committee of the First Affiliated Hospital, College of Medicine, Zhejiang University and informed consent was obtained from each patient or their family prior to surgery.

RNA isolation and reverse transcription-quantitative polymerase chain reaction $(R T-q P C R)$. Total RNA was extracted from cells using TRIzol ${ }^{\circledR}$ (Invitrogen; Thermo Fisher Scientific, Inc.). Total RNA from tissue samples was extracted using the RNAprep Pure Tissue kit (Tiangen Biotech Co., Ltd., Beijing, China). Complementary DNA was synthesized from RNA using the PrimeScript RT Master Mix reagent kit (Takara Biotechnology, Co., Ltd., Dalian, China). The primer sequences used for reverse transcription were as follows: miR-223, 5'-GTCGTATCCAGTGCAGGGTCCGAGGTA TTCGCACTGGATACGACTGGGGT-3'; U6, 5'-AAAATA TGGAACGCT-3' and IGF-1R, 5'-TGCATACAGAATTAT TTTATTT-3'. The oligo dT primer was used for the other genes. qPCR was performed using the SYBR premix EX Taq kit (Takara Biotechnology, Co., Ltd.). The thermocycling conditions were as follows: $95^{\circ} \mathrm{C}$ for $30 \mathrm{sec}$, and 40 cycles of $95^{\circ} \mathrm{C}$ for $5 \mathrm{sec}$ and $60^{\circ} \mathrm{C}$ for $34 \mathrm{sec}$. U6 was used as control for miR-223. GAPDH was used as control for the other genes. The primers used for qPCR were as follows: miR-223, forward, 5'-GTGCAGGGTCCGAGGT-3' and reverse, 5'-CGGGCT GTCAGTTTGTCA-3'; U6, forward, 5'-CTCGCTTCGGCA GCACA-3' and reverse, 5'-AACGCT TCACGAATTTGC GT-3'; IGF-1R, forward, 5'-GGACAGGTCAGAGGGTTT C-3' and reverse, 5'-CTCGTAACTCTTCTCTGTGCC-3'; Akt, forward, 5'-ATCGTCGCCAAGGATGAGGT-3' and reverse, 5'-TCTCGTGGTCCTGGTTGTAG-3'; ERK, forward, 5'-CCT AAGGAAAAG-CTCAAAGA-3' and reverse, 5'-AAAGTG GATAA-GCCAAGAC-3'; GAPDH, forward, 5'-ATGGGT GTGAACCATGAGAAGTATG-3' and reverse, 5'-GGTGCA GGAGGCATTGCT-3'. The relative expressions of the target genes were normalized to GAPDH expression using the $2^{-\Delta \Delta \mathrm{Cq}}$ method (17).

Western blot analysis. Cells were lysed in sodium dodecyl sulfate (SDS) lysis buffer (Beyotime Institute of Biotechnology, Shanghai, China). Protein concentrations were determined using the Bradford Protein Assay kit (Beyotime Institute of Biotechnology). For each sample, $30 \mu \mathrm{g} /$ lane of total proteins were separated using $12 \%$ SDS-PAGE. Proteins were then transferred onto nitrocellulose membranes (EMD Millipore, Billerica, MA, USA), blocked with $5 \%$ bovine serum albumin (Gibco; Thermo Fisher Scientific, Inc.) at room temperature for $2 \mathrm{~h}$. The membranes were probed with the relevant primary antibodies overnight at $4^{\circ} \mathrm{C}$. The primary antibodies used were as follows: Rabbit polyclonal to IGF-1R (G1155; 1:1,000; cat. no. BS1182; Biocompare, South San Francisco, CA, USA); rabbit polyclonal to ERK 1/2 (1:1,000; cat. no. ab196883); rabbit polyclonal to phosphorylated (p)-ERK 1/2 (1:1,000; cat. no. ab214362); rabbit polyclonal to Akt (1:1,000; cat.no. ab8805); 
A

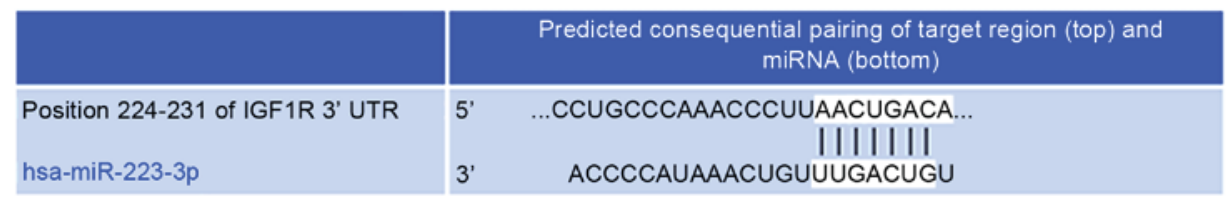

B

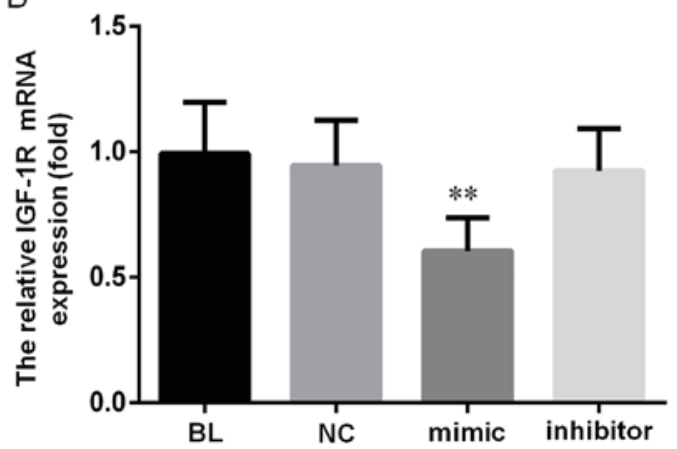

C

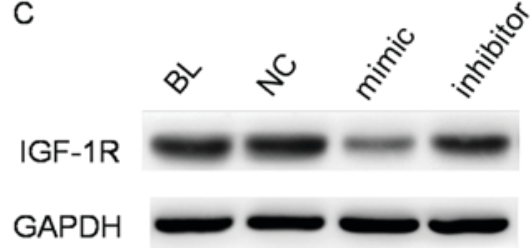

Figure 1. miR-223 regulates IGF-1R expression in the Hep3B cell line. (A) The 224-231 of the IGF-1R 3'-untranslated region is the putative target site of miR-223. (B) Relative mRNA expression of IGF-1R in cells transfected with miR-223 mimic, miR-223 inhibitor and NC, compared with the BL. The expression of IGF-1R mRNA was normalized to GAPDH. (C) Expression of IGF-1R protein detected by western blotting in cells transfected with miR-223 mimic, miR-223 inhibitor or NC, compared with the BL group. GAPDH was used as a loading control. Quantified data are presented as the mean \pm standard deviation. ${ }^{* *} \mathrm{P}<0.01$ vs. BL. BL, blank control; NC, negative control RNA; mimic, miR-223 mimic; inhibitor, miR-223 inhibitor; IGF-1R, insulin-like growth factor-1 receptor; miR-223, microRNA-223.

rabbit polyclonal to p-Akt (1:1,000; cat. no. ab38449); and rabbit polyclonal to GAPDH $(1: 1,000$; cat. no. ab9485; all Abcam, Cambridge, MA, USA). Membranes were then incubated with horseradish peroxidase-conjugated goat-anti rabbit immunoglobulin G secondary antibody (cat. no. SC-2030, 1:2,000; Santa Cruz Biotechnology, Inc., Dallas, TX, USA). Signals were detected using an enhanced chemiluminescence kit (Pierce; Thermo Fisher Scientific, Inc.).

Cell proliferation assay. Cell proliferation was measured using a Cell Counting Kit-8 (CCK-8) assay. A total of $24 \mathrm{~h}$ after transfection, 3,000 cells/well were seeded into a 96-well plate. CCK-8 reagent (Sangon Biotech, Co., Ltd., Shanghai, China) was added $72 \mathrm{~h}$ following seeding. Optical density was measured at $450 \mathrm{~nm}$ using a microplate reader.

Cell apoptosis assay. Cell apoptosis was measured using Annexin V apoptosis assay kit and 7-amino-actinomycin D staining kit (both Sangon Biotech, Co., Ltd.) and measured on BD LSRFortessa Cell Analyzer and analyzed by BD FACSDIVA software version 8.0.1 (BD Biosciences, Franklin Lakes, NJ, USA).

Statistical analysis. All statistical analyses were performed using SPSS software version 16.0 (SPSS, Inc., Chicago, IL, USA). Continuous variables were expressed as the mean \pm standard deviation. Comparison of the relative mRNA expression and cell proliferation rate among multiple groups was assessed by one-way analysis of variance followed by Fisher's Least Significant Difference test. Correlations between miR-223 and IGF-1R mRNA levels in tumor tissues were analyzed using the linear regression method. $\mathrm{P}<0.05$ was considered to indicate a statistically significant difference.

\section{Results}

miR-223 regulates IGF-1R expression in HCC. It was determined whether the expression of IGF-1R is regulated by miR-223. The position 224-231 within the 3'-untranslated coding region of IGF-1R was predicted to be the binding region of miR-223 (Fig. 1A). Following transfection of miR-223 mimic, the relative expression of IGF-1R mRNA was reduced by $38.8 \%$ compared with the blank control $(\mathrm{P}<0.01$; Fig. $1 \mathrm{~B})$. The expression of IGF-1R protein was also reduced in cells transfected with miR-223 mimic (Fig. 1C). However, transfection with the miR-223 inhibitor did not alter the levels of IGF-1R mRNA or protein. These results indicate that IGF-1R expression is regulated by miR-223.

The effect of miR-223 on HCC cell proliferation and apoptosis. Subsequently, the role of miR-223 on Hep3B cell proliferation and apoptosis was investigated. The results of the CCK-8 assay demonstrated that cell proliferation was significantly suppressed following transfection of miR-223 mimic $(\mathrm{P}<0.01$; Fig. 2A). The relative expression of IGF-1R mRNA was reduced by $11.3 \%$ compared with controls $(\mathrm{P}<0.01$; Fig. 2A). Furthermore, the rate of cell apoptosis was significantly increased following transfection with miR-223 mimic compared with the control, from 8.16 to $28.16 \%$ $(\mathrm{P}<0.01$; Fig. 2B and C). Transfection with NC or miR-223 inhibitor did not significantly affect cell proliferation or apoptosis compared with the control. These results indicate that upregulation of miR-223 may reduce the tumorigenicity of HCC cells in vitro.

miR-223 reduces $p$-Akt and $p$-ERK expression. Since activation of Akt and ERK are essential for tumor progression, it 


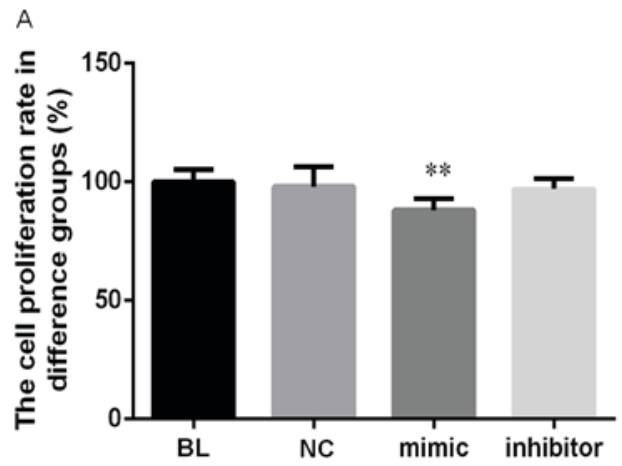

B

$\mathrm{BL}$

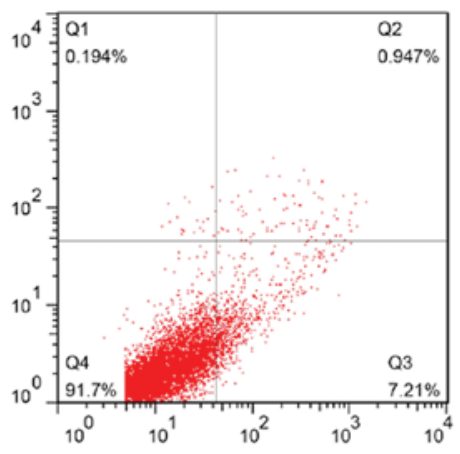

mimic

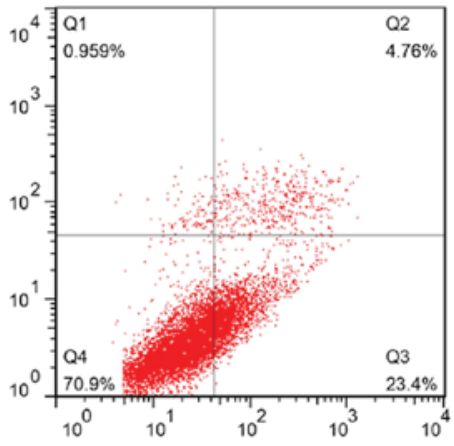

C

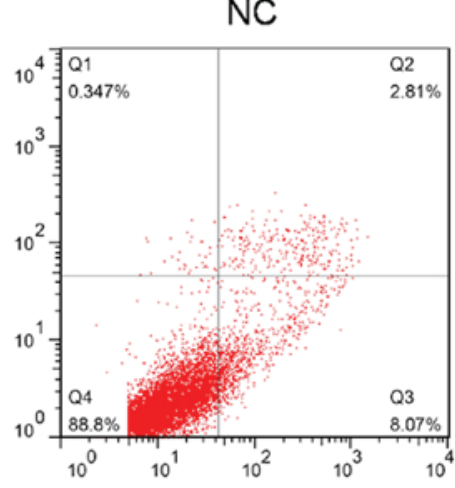

inhibitor

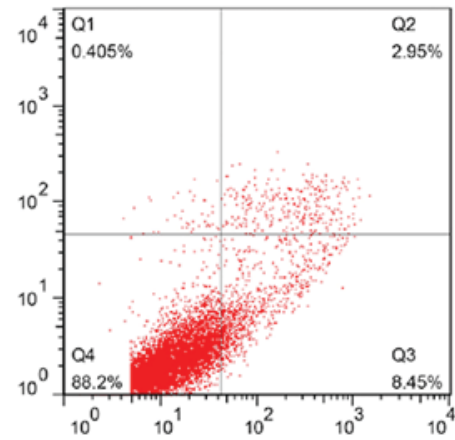

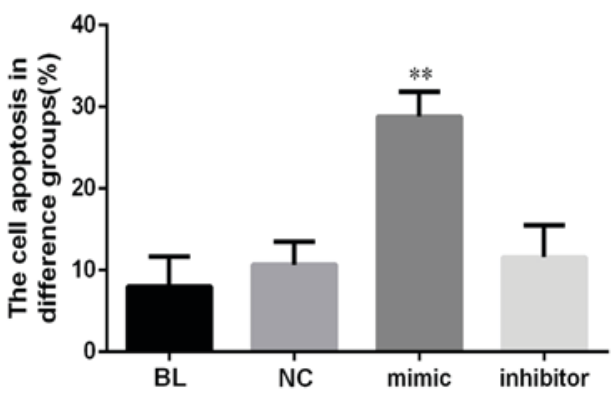

Figure 2. miR-223 suppresses the proliferation and increases the apoptosis of Hep3B cells. Cells were transfected with miR-223 mimic, miR-223 inhibitor or NC and compared with the BL group. (A) Cell proliferation was measured using the cell counting kit-8 assay. (B) Cell apoptosis assay. Cells (10,000/treatment) were stained with Annexin V-fluorescein isothiocyanate and propidium iodide and assessed using flow cytometry. (C) Quantification of cell apoptosis. Quantified data are presented as the mean \pm standard deviation. ${ }^{* *} \mathrm{P}<0.01$ vs. BL. BL, blank control; NC, negative control RNA; mimic, miR-223 mimic; inhibitor, miR-223 inhibitor; miR-223, microRNA-223.

was investigated whether miR-223 overexpression affected the expression and phosphorylation of these molecules. The results of western blotting indicated that levels of p-Akt and p-ERK were reduced following transfection with miR-223 mimic (Fig. 3A). Notably, levels of total Akt and ERK were also reduced. Levels of Akt and ERK mRNA were also measured and it was demonstrated that levels of Akt and ERK mRNA were significantly decreased following transfection 
A
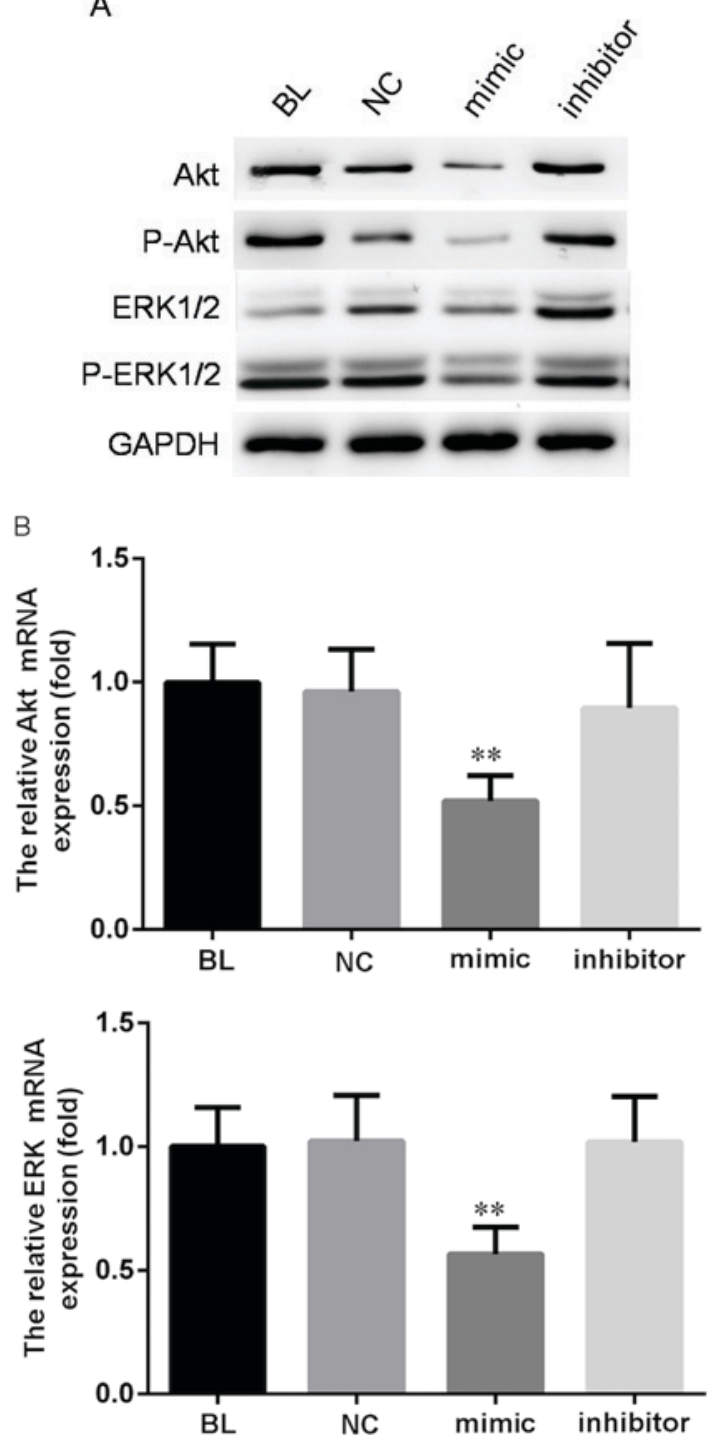

Figure 3. miR-223 regulates downstream signaling of the IGF-1 pathway. The expression of Akt and ERK were measured in cells transfected with miR-223 mimic, miR-223 inhibitor or NC and compared with the BL group. (A) The expression of total Akt, total ERK, and their active forms p-Akt and p-ERK were measured by western blot analysis. (B) Relative mRNA level of Akt and ERK normalized to GAPDH. Quantified data are presented as the mean \pm standard deviation. ${ }^{* *} \mathrm{P}<0.01$ vs. BL. BL, blank control; $\mathrm{NC}$, negative control RNA; mimic, miR-223 mimic; inhibitor, miR-223 inhibitor; IGF-1R, insulin-like growth factor-1 receptor; miR-223, microRNA-223; p-, phosphorylated; Akt, protein kinase B; ERK, extracellular-signal regulated kinase.

( $\mathrm{P}<0.01$; Fig. 3B). These results indicate that miR-223 affects downstream signaling of the IGF-1 pathway at the mRNA and protein levels.

miR-223 expression is negatively correlated with $I G F-1 R$ expression. To confirm the correlation between miR-223 and IGF-1R, their levels were measured in $30 \mathrm{HCC}$ tissues. As presented in Fig. 4, a significant inverse correlation was identified between miR-223 and IGF-1R mRNA expression (regression equation: $\mathrm{Y}=-2.5178 \mathrm{X}+2.6642$, $\mathrm{r}=-0.965)$. Therefore, taken together, the results of the present study indicate that IGF-1R is directly regulated by miR-223.

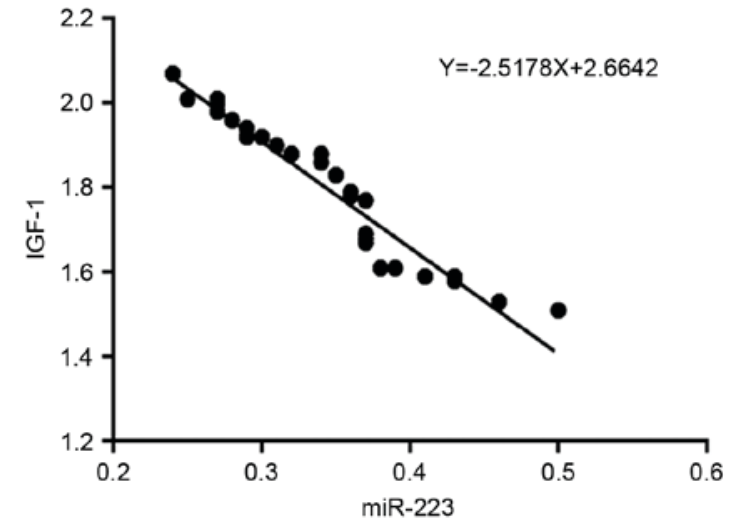

Figure 4. Correlation between miR-223 and IGF-1R expression in tumor tissues of patients with hepatocellular carcinoma. $\mathrm{r}=-0.965 ; \mathrm{P}<0.001$. miR-223, microRNA-223; IGF-1R, insulin-like factor 1 receptor.

\section{Discussion}

It has been determined that miR-223 expression is downregulated in HCC tumor tissue compared with matching adjacent normal liver tissue (6). Therefore, the aim of the present study was to assess whether miR-223 may act as a tumor suppressor in HCC by inhibiting cell proliferation and promoting apoptosis. Furthermore, the current study aimed to identify the method by which miR-223 acts as a tumor suppressor. One potential mechanism by which it may act may be via the direct modulation of IGF-1R and the downstream regulation of Akt and ERK. Jung and Suh (13) indicated that the Akt and ERK pathways are involved in cell proliferation and apoptosis by regulating the expression of $\mathrm{Bcl}-2$, p27, forkhead box protein (FOXO) transcription factors and BAD.

The most common risk factors for HCC are chronic infection with viral hepatitis $\mathrm{B}$ and $\mathrm{C}$, and dietary exposure to aflatoxin $B_{1}(2)$. Since miR-223 may be a negative regulator of inflammation (8), the chronic inflammatory response in the liver may be explained by miR-223 repression. Although miR-223 is commonly downregulated in HCC tumor tissue, its levels of expression in the sera of patients with HCC are variable. Xu et al (18) reported elevated miR-223 levels, whereas Bhattacharya et al (7) reported reduced miR-223 levels in the sera of patients with HCC. These contrasting results suggest that serum miR-223 may not be suitable as a standard biomarker for HCC; further studies are required to evaluate its diagnostic value.

The role of miR-223 in cell proliferation has been observed in multiple HCC cell lines. Wong et al (6) identified that miR-223 expression was reduced in $11 \mathrm{HBV}$-related cell lines, 4 HCV-related cell lines and 3 non-B or non-C-related cell lines, including the Hep3B cell line used in the current study. The results of a previous study also indicated that the IGF-1 signaling pathway is a crucial regulatory route of miR-223 in HeLa cells (10). IGF-1-mediated regulation by miR-223 has also been reported in Lewis lung carcinoma cells (19). Furthermore, it has been demonstrated that the transcription factor FOXO1 mediates the influence of miR-223 on the proliferation of HCT116 colorectal cancer cells, HeLa cervical cancer cells and HuH-7 hepatoma cells (20). Activation of the Akt pathway results in the downstream activation FOXO1; therefore, the involvement 
of miR-223 in the IGF-1 pathway does not merely occur via IGF-1R, other factors are also involved. However, regulation of the IGF-1 pathway using miRNAs or miRNA-targeting oligonucleotides is an attractive strategy for the treatment of cancer. Several ongoing clinical trials have already tested the efficiency and safety of drugs targeting IGF-1R, including the IGF-1R antibodies MK-0646 and the IGF-1R tyrosine kinase inhibitor OSI-906 $(21,22)$.

The regulation of miR-223 expression may, at least partially, be induced by the $\mathrm{p} 53 \mathrm{R} 175 \mathrm{H}$ gain-of function mutation. This mutation inhibits the miR-223 promoter in colon and breast cancer cell lines and is associated with chemoresistance in tumor cells (23). Inhibition of oncogenic Notch signaling may induce miR-223 expression in T-lineage acute lymphoblastic leukemia cells, implicating that Notch may be another regulator of miR-223 expression in cancer cells (24).

Although miR-223 has proven to be a tumor suppressor in HCC, miR-223 may serve opposing roles in the migration and invasion of different types of cancer cells. In esophageal cancer cells, miR-223 seems to suppress cell migration and invasion (25), whereas in metastatic gastric cancer cells and recurrent ovarian cancer, miR-223 is overexpressed and promotes metastasis $(26,27)$. These contrasting results indicate that further studies are required to determine the roles miR-223 serves in different types of cancer.

Theoretically, repression of miR-223 is supposed to promote IGF-1R production. However, in the present study, transfection with miR-223 inhibitor did not significantly increase IGF-1R production compared with the control. This may be due to the fact that miR-223 is already downregulated in HCC tumor cells and further inhibition of miR-223 may not lead to the marked promotion of IGF-1R expression. Another possible explanation is that IGF-1R is under the regulation of many factors and the effect of inhibiting miR-223 expression may be restricted by those other factors.

In conclusion, it has been demonstrated that miR-223 serves a role as a tumor suppressor in HCC cells by regulating IGF-1R expression. There were a few limitations of the current study. Only one HCC cell line was tested; experiments in other HCC cell lines should be performed to verify if the regulation of IGF-1R by miR-223 is universal in HCC cells. Furthermore, the current study was an in vitro study; in vivo studies, for example, studies investigating the effects of miR-223 on tumor formation in nude mice, are required to confirm the regulating role of miR-223 via the IGF-1 pathway. miR-223 may have other targets besides IGF-1R, therefore future studies should investigate whether miR-223 also regulates other target genes in HCC.

\section{Acknowledgements}

Not applicable.

\section{Funding}

No funding was received.

\section{Availability of data and materials}

The datasets used and/or analyzed during the current study are available from the corresponding author on reasonable request.

\section{Authors' contributions}

JZ designed and supervised the study. CZ performed the experiments and analyzed the data. $\mathrm{CZ}$ and $\mathrm{JZ}$ discussed the results and wrote the study together.

\section{Ethics approval and consent to participate}

The study protocol was approved by the Ethics Committee of the First Affiliated Hospital, College of Medicine, Zhejiang University and informed consent was obtained from each patient or their family prior to surgery.

\section{Consent for publication}

Not applicable.

\section{Competing interests}

The authors declare that they have no competing interests.

\section{References}

1. El-Serag HB and Rudolph KL: Hepatocellular carcinoma: Epidmeiology and molecular carcinogenesis. Gastroenterology 132: 2557-2576, 2007.

2. Chen W, Zheng R, Baade PD, Zhang S, Zeng H, Bray F, Jemal A, Yu XQ and He J: Cancer statistics in China, 2015. CA Cancer J Clin 66: 115-132, 2016.

3. Kew MC: Hepatocellular carcinoma: Epidemiology and risk factors. J Hepatocellular Carcinoma 1: 115-125, 2014

4. Chen K and Rajewsky N: The evolution of gene regulation by transcription factors and microRNAs. Nat Rev Genet 8: 93-103, 2007.

5. Li LM, Hu ZB, Zhou ZX, Chen X, Liu FY, Zhang JF, Shen HB, Zhang CY and Zen K: Serum microRNA profiles serve as novel biomarkers for HBV infection and diagnosis of HBV-positive hepatocarcinoma. Cancer Res 70: 9798-9807, 2010.

6. Wong QW, Lung RW, Law PT, Lai PB, Chan KY, To KF and Wong N: MicroRNA-223 is commonly repressed in hepatocellular carcinoma and potentiates expression of stathmin1. Gastroenterology 135: 257-269, 2008.

7. Bhattacharya S, Steele R, Shrivastava S, Chakraborty S, Di Bisceglie AM and Ray RB: Serum miR-30e and miR-223 as novel noninvasive biomarkers for hepatocellular carcinoma. Am J Pathol 186: 242-247, 2016.

8. Ramkissoon SH, Mainwaring LA, Ogasawara Y, Keyvanfar K, McCoy JP Jr, Sloand EM, Kajigaya S and Young NS: Hematopoietic-specific microRNA expression in human cells. Leuk Res 30: 643-647, 2006.

9. Fazi F, Racanicchi S, Zardo G, Starnes LM, Mancini M, Travaglini L, Diverio D, Ammatuna E, Cimino G, Lo-Coco F, et al: Epigenetic silencing of the myelopoiesis regulator microRNA-223 by the AML1/ETO oncoprotein. Cancer Cell 12: 457-466, 2007.

10. Jia CY, Li HH, Zhu XC, Dong YW, Fu D, Zhao QL, Wu W and $\mathrm{Wu}$ XZ: miR-223 suppresses cell proliferation by targeting IGF-1R. PLoS One 6: e27008, 2011.

11. Li G, Cai M, Fu D, Chen K, Sun M, Cai Z and Chen B: Heat shock protein $90 \mathrm{~B} 1$ plays an oncogenic role and is a target of microRNA-223 in human osteosarcoma. Cell Physiol Biochem 30: 1481-1490, 2012.

12. Lu TX, Lim E, Besse JA, Itskovich S, Plassard AJ, Fulkerson PC, Aronow BJ and Rothenberg ME: miR-223 deficiency increases eosinophil progenitor proliferation. J Immunol 190: 1576-1582, 2013.

13. Jung HJ and Suh Y: Regulation of IGF-1 signaling by microRNAs. Front Genet 5: 472, 2015.

14. Fürstenberger $\mathrm{G}$ and Senn $\mathrm{H}$ : Insulin-like growth factors and cancer. Lancet Oncol 3: 298-302, 2002.

15. Martini M, De Santis M, Braccini L, Gulluni F and Hirsch E: PI3K/AKT signaling pathway and cancer: An updated review. Ann Med 46: 372-383, 2014. 
16. Samani A, Yakar S, LeRoith D and Brodt P: The role of the IGF system in cancer growth and metastasis: Overview and recent insights. Endocr Rev 28: 20-47, 2006.

17. Livak KJ and Schmittgen TD: Analysis of relative gene expression data using real-time quantitative PCR and the 2(-Delta Delta C(T)) method. Methods 25: 402-408, 2001.

18. Xu J, Wu C, Che X, Wang L, Yu D, Zhang T, Huang L, Li H, Tan W, Wang C and Lin D: Circulating MicroRNAs, miR-21, miR-122, and miR-223, in patients with hepatocellular carcinoma or chronic hepatitis. Mol Carcinog 50: 136-142, 2011.

19. Nian W, Ao X, Wu Y, Huang Y, Shao J, Wang Y, Chen Z, Chen F and Wang D: miR-223 functions as a potent tumor suppressor of the Lewis lung carcinoma cell line by targeting insulin-like growth factor-1 receptor and cyclin-dependent kinase 2. Oncol Lett 6: 359-366, 2013.

20. Wu L, Li H, Jia CY, Cheng W, Yu M, Peng M, Zhu Y, Zhao Q, Dong YW, Shao K, et al: MicroRNA-223 regulates FOXO1 expression and cell proliferation. FEBS Lett 586: 1038-1043, 2012.

21. Reidy-Lagunes DL, Vakiani E, Segal MF, Hollywood EM, Tang LH, Solit DB, Pietanza MC, Capanu M and Saltz LB: A phase 2 study of the insulin-like grow th factor-1 receptor inhibitor MK-0646 in patients with metastatic, well-differentiated neuroendocrine tumors. Cancer 118: 4795-4800, 2012.

22. Pitts TM, Tan AC, Kulikowski GN, Tentler JJ, Brown AM, Flanigan SA, Leong S, Coldren CD, Hirsch FR, Varella-Garcia M, et al: Development of an integrated genomic classifier for a novel agent in colorectal cancer: Approach to individualized therapy in early development. Clin Cancer Res 16 : 3193-3204, 2010
23. Masciarelli S, Fontemaggi G, Di Agostino S, Donzelli S, Carcarino E, Strano S and Blandino G: Gain-of-function mutant p53 downregulates miR-223 contributing to chemoresistance of cultured tumor cells. Oncogene 33: 1601-1608, 2014.

24. Gusscott S, Kuchenbauer F, Humphries RK and Weng AP: Notch-mediated repression of miR-223 contributes to IGF1R regulation in T-ALL. Leuk Res 36: 905-911, 2012.

25. Li S, Li Z, Guo F, Qin X, Liu B, Lei Z, Song Z, Sun L, Zhang HT, You J and Zhou Q: miR-223 regulates migration and invasion by targeting Artemin in human esophageal carcinoma. J Biomed Sci 18: 24, 2011.

26. Li X, Zhang Y, Zhang H, Liu X, Gong T, Li M, Sun L, Ji G, Shi Y, Han Z, et al: miRNA-223 promotes gastric cancer invasion and metastasis by targeting tumor suppressor EPB41L3. Mol Cancer Res 9: 824-833, 2011.

27. Laios A, O'Toole S, Flavin R, Martin C, Kelly L, Ring M, Finn SP, Barrett C, Loda M, Gleeson N, et al: Potential role of miR-9 and miR-223 in recurrent ovarian cancer. Mol Can 7: 35, 2008.

This work is licensed under a Creative Commons Attribution-NonCommercial-NoDerivatives 4.0 International (CC BY-NC-ND 4.0) License. 